\title{
THE IMPORTANCE OF DEVELOPMENT FOR COMPARATIVE PRIMATOLOGY
}

\author{
Kim A. Bard ${ }^{1, *}$ and David A. Leavens ${ }^{2, *}$ \\ ${ }^{1}$ Psychology Department, University of Portsmouth, Portsmouth, Hampshire PO1 2DY, \\ United Kingdom; email: kim.bard@port.ac.uk \\ ${ }^{2}$ School of Psychology, University of Sussex, Falmer, East Sussex BN1 9QH United \\ Kingdom; email: davidl@,sussex.ac.uk \\ *Both authors contributed equally to this work.
}

Keywords great apes, joint attention, lived experiences, chimpanzees

- Abstract It is a truism to say that primates develop, but it is also important to acknowledge that development occurs across many domains, including motor behavior, socioemotional behavior, communication, and cognition. In this review, we focus on those aspects of development that impact social cognition outcomes in infancy. Triadic engagements, such as those of joint attention, cooperation, and intentional communication, develop in the first year of life in chimpanzees and humans. Joint attention, for example, occurs when infants coordinate their attention to a social partner while also attending to an object or event. Hominoids are strongly influenced by experiences during early development, especially experiences that are foundational for these coordinated triadic engagements. Purported species differences in triadic engagements are highlighted in current evolutionary theories of primate social cognition, but conclusions about species differences are unfounded when development is ignored. Developmental experiences must be matched, controlled, or systematically varied in experimental designs that make cross-species comparisons. Considerations of development, across species and across rearing experiences, would contribute to more accurate evolutionary theories of primate social cognition.

\section{DEVELOPMENTAL CONSIDERATIONS IN PRIMATE SOCIAL COGNITION}

Since the 1960s, scientists have offered different theories to explain the evolution of primate social cognition. Beginning with Jolly (1966), investigators proposed a distinct evolutionary path for social intelligence because social intelligence was based on the need to function in complex societies and both supported social learning and depended 
on it. Humphrey (1976) was also interested in the adaptations that allowed for learning flexibly during ontogeny, in particular, learning the complexities of sociality. Parker \& Gibson (1979) presented one of the first evolutionary theories of primate cognition, and it was explicitly developmental (Table 1). Recent influential theories of the evolution of primate social cognition, however, neglect to consider development in nonhuman primates; ignoring development is a significant problem because primates and their social cognition develop as a result of social and emotional experiences. For example, many theories consider only the abilities of adults in species other than human and disregard the influence of developmental experiences on outcomes (but see Boesch 2012; Jablonka \& Lamb 2007; Suomi 2004 for alternative perspectives). The shared intentionality model (Tomasello et al. 2005), the cultural intelligence hypothesis (Herrmann et al. 2007), the Vygotskian intelligence theory (Moll \& Tomasello 2007),

Table 1 Developmental considerations in selected theories of primate social cognition

\begin{tabular}{|l|l|l|l|}
\hline \multirow{2}{*}{ Theory/model } & \multicolumn{2}{|l|}{ Is development considered for } \\
\cline { 2 - 4 } & Humans? & Apes $^{\mathbf{j}}$ & Monkeys $^{\mathbf{j}}$ \\
\hline Social intelligence $^{\mathrm{a}}$ & Yes & Yes & Yes \\
\hline $\begin{array}{l}\text { Piagetian } \\
\text { development }^{\mathrm{b}}\end{array}$ & Yes & Yes & Yes \\
\hline Theory of mind $^{\mathrm{c}}$ & Yes & No & na \\
\hline $\begin{array}{l}\text { Machiavellian } \\
\text { intelligence }^{\mathrm{d}}\end{array}$ & No & No & No \\
\hline Social brain $^{\mathrm{e}}$ & No & No & No \\
\hline Shared intentionality $^{\mathrm{f}}$ & Yes & No & na \\
\hline Cultural intelligence $^{\mathrm{g}}$ & Yes & No & na \\
\hline $\begin{array}{l}\text { Vygotskian } \\
\text { intelligence }^{\mathrm{h}}\end{array}$ & Yes & No & na \\
\hline Cumulative culture $^{\mathrm{i}}$ & Yes & No & No \\
\hline
\end{tabular}

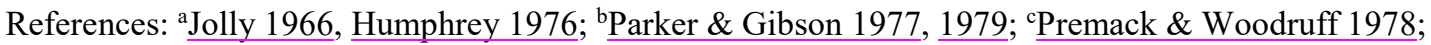
${ }^{\mathrm{d}}$ Byrne \& Whiten 1988, Whiten \& Byrne 1988; ${ }^{\mathrm{e} D u n b a r ~ 1998 ;}{ }^{\mathrm{T}}$ Tomasello et al. 2005; ' Herrmann et al. 2007;

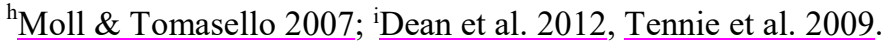

j"Yes" indicates that developmental change in this group was considered specifically in the indicated paper; "no" indicates that development, developmental experiences, and/or developmental change for this group was not considered in the indicated paper; "na" (not applicable) indicates that this group was not considered in the indicated paper. 
and the cumulative culture model (Dean et al. 2012; Tennie et al. 2009; Tomasello et al. 1993a) are offered as theoretical and evolutionary explanations of "human-unique" social cognition. Unfortunately, the study designs upon which these theories are built cannot identify social cognition that is unique to humans, undermining the core premises of these theories. These studies have the following three fatal flaws, which are the subject of this article: $(a)$ a reliance on an experimental design that inaccurately depicts group-specific differences as "species" differences because the design neglects the impact of developmental experiences as confounds; $(b)$ a lack of consideration of development in nonhuman primates; and $(c)$ exclusive reliance on a single human group without evidence that their social cognition outcomes are universal, especially among humans from different ecocultural settings (e.g., Keller 2007).

\section{HOW NEGLECT OF DEVELOPMENT IN PRIMATE SOCIAL COGNITION IMPACTS THE DATABASE: INVALID EXPERIMENTAL DESIGNS}

Consider the hypothetical research design proposed by Leavens et al. (2008). Neonatal representatives of two closely related, but genetically distinct groups, human boys and human girls, are assigned to two different treatment groups. Boys are assigned to rearing circumstances like those of institutionalized Romanian orphans, experiencing daily social and physical impoverishment and neglect. In contrast, the girls are assigned to a treatment in which they are raised by their biological families, experiencing frequent daily episodes of laughter, shared joy, cuddling, joint attention, and responsive care. At 9--12 months of age, we assess each group's ability to engage in joint attention with adults. We would likely find that the girl group outperformed the boy group (see the next section for brief review of the consequences of deprivation on social cognition). The interpretive question of vital importance not only to this paper, but to the comparative evolutionary discipline is, Can we conclude that there is a genetically based sex difference in joint attention between human boys and human girls given this research design?

The answer to this question is obvious: No. This research design cannot support the conclusion that girls are superior to boys in joint attention (i.e., generalizing to all girls and all boys or identifying genes as the critical variable). The differences in developmental experiences (i.e., rearing history) between the boy group and the girl 
group are irretrievably confounded with their systematic genetic differences. Certainly, there is no reason to think that we would find the same superiority of girls in joint attention if the assignments to the two different rearing conditions was reversed, i.e., if the girls were assigned to the impoverished rearing condition.

Now consider Figure 1, which depicts precisely the same flawed research design. It depicts two groups of organisms whose genetic profiles systematically differ, although here, by simple substitution, the groups comprise human and ape neonates. It assigns the two groups to the same two rearing conditions as above: the ape group to experience impoverishment and neglect during development and the human group to experience warm, loving family life during development. Using the same outcome measure of joint attention, the likely result is a significant group difference, the human group displaying superior performance. Can we conclude from this research design that there is a genetically based species difference between apes and humans in joint attention? Of course not, for all the reasons outlined above.

In this experimental design, a third variable reflects yet another way in which development in nonhumans is disregarded. Added to the groups' systematic differences in genes and developmental experiences is the third confound: age at testing. In this design, the human group is tested during infancy (9--12 months), but the chimpanzee group is tested as juveniles ( 4 years in captivity; Fragaszy \& Bard 1997). Clearly, because no rational investigator would assert that there is a sex difference in the first research design with a two-way confound, we might reasonably expect, on logical grounds, that no contemporary researcher would assert that there is a species difference in the second research design, especially with a three-way confound (Figure 1). Unfortunately, this is far from the case: The results of such confounded experimental studies form the database for many of the contemporary evolutionary theories that claim "human-unique" social cognition (Table 1).

No amount of pleading can rehabilitate the illogical conclusion that girls (or humans) are innately superior to boys (or apes) in joint attention on the basis of these experimental designs (Figure 1). We cannot, for example, argue that because it would be really difficult or very expensive to equate the developmental experiences of these boys and girls (or apes and humans) that we should accept at face value the conclusion of sex (or species) difference. We have no basis on which to conclude that it is more 
natural for girls (or humans) to be raised with positive affective experiences and for boys (or apes) to be raised in institutional settings. The design presented in Figure 1 can never isolate genes as the explanatory factor accounting for the observed group differences in social cognition outcomes.

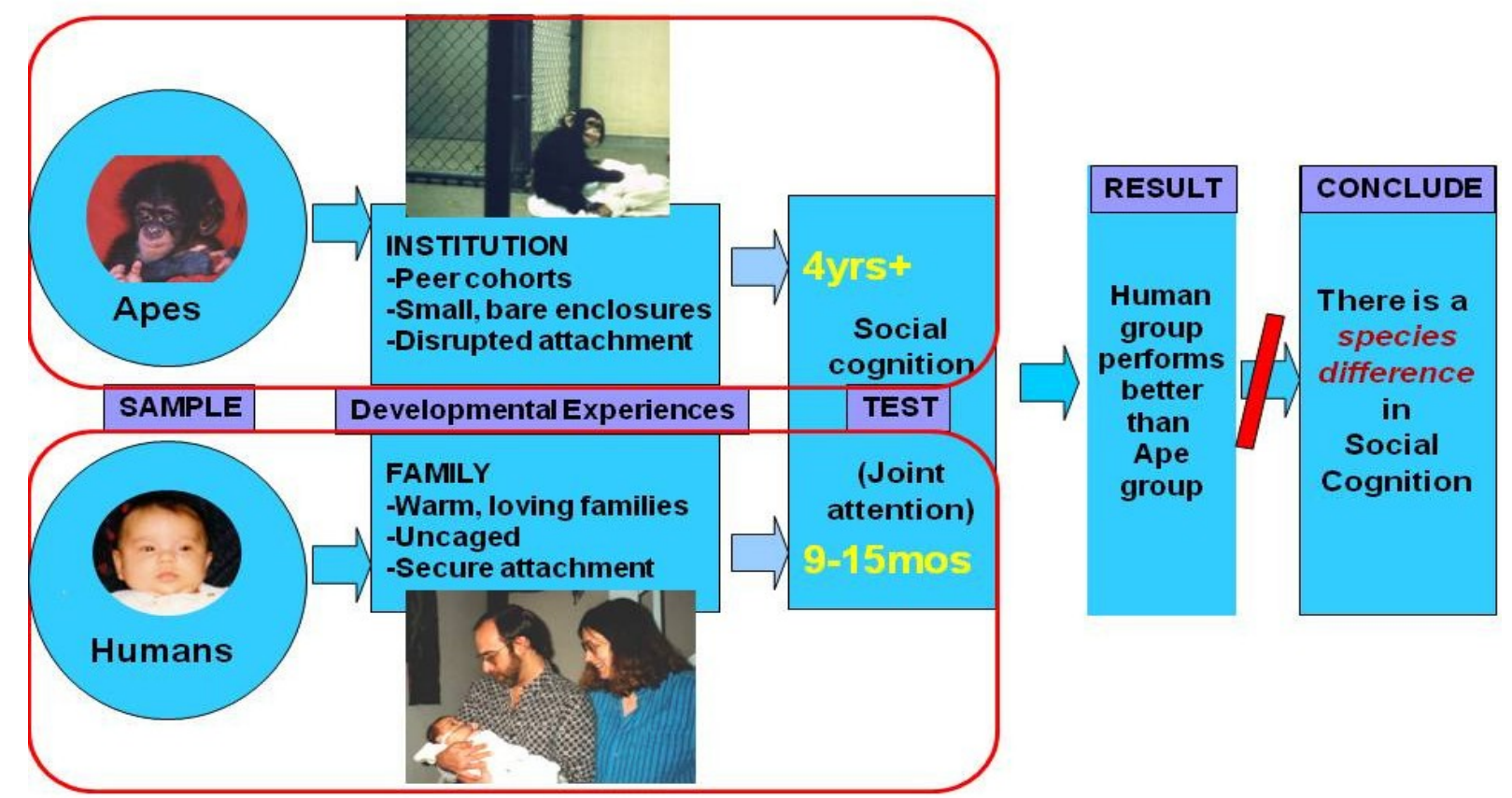

Adapted from Leavens, Hopkins, \& Bard, 2005; 2008

Figure 1 Design flaws of current comparative studies. In this experimental design, developmental experiences and age at testing are not matched across groups and are confounded with genetic differences. Because developmental experiences strongly influence social cognition outcomes in apes and humans, this design can never isolate species as the explanatory factor accounting for group differences in social cognition.

\section{THE DEVELOPMENT OF SOCIAL COGNITION IN HUMANS}

Few theories deny the importance of development for social cognitive outcomes in humans. We find it surprising, however, that development is often ignored for nonhuman primates, especially when considering that apes, our closest evolutionary relatives, have a long period of infancy during which they are responsive to environmental stimuli. For human infants, we have known for decades that engagement with social partners and engagement with objects are essential developmental precursors for joint attention (e.g., Bakeman \& Adamson 1984; Trevarthen \& Aitken 2001). For 
chimpanzees, we have known for decades that outcomes vary as a function of developmental experiences (see reviews by Bard \& Leavens 2009; Leavens \& Bard 2011), but these developmental effects have generally been ignored in theory building (Table 1). There is a puzzling and widespread bias toward attributing poor performance in nonhuman primates to genetic factors (e.g., the species lacks a capacity) and yet attributing similar poor performance in humans to developmental factors (e.g., infants lack a capacity). In the following sections, we review early development of joint attention in humans and chimpanzees, identifying differential outcomes as a function of early developmental experiences. Using this evidence, we discuss why the consideration of development is absolutely essential when building meaningful and valid theories of the evolution of primate social cognition.

We focus on the prototypical form of infant social cognition, that is, joint attention. Joint attention is a triadic ability, known as a "referential triangle," "coordinated joint engagement" (Bakeman \& Adamson 1984), or "intentional co-orientation to a common focus" (Leavens \& Racine 2009), in which infants coordinate their attention to a social partner with their attention to an object or event. According to one of the most widely cited theories of primate social cognition, joint attention marks the developmental onset of shared intentionality (Tomasello et al. 2005). This form of social cognition is thought by some to be a precursor to "theory of mind" (Nelson et al. 2007; Tomasello et al. 2005) or second-order intentionality (e.g., Rakoczy 2009).

\section{Human Normative Development}

Figure 2 illustrates the development of joint attention. In humans, joint attention emerges between 9 and 12 months and depends on a developmental history of early mutual engagement with social partners (peaking at 3 months) and a developmental history of early engagement with objects (from 5 months of age). In many urban and Western cultures, young human infants engage in face-to-face interactions with caregivers, with positive affective exchanges (i.e., primary intersubjectivity: Trevarthen 1979; interpersonal engagement: Adamson 1996). By five months of age, human infants in these settings tend to shift their attention away from en face interactions with caregivers and toward exclusive interaction with objects. There appears to be a universal developmental milestone of increased manipulation of objects around 5--7 months of age (e.g., Bakeman et al. 1990). 


\section{The Development of Joint Attention}

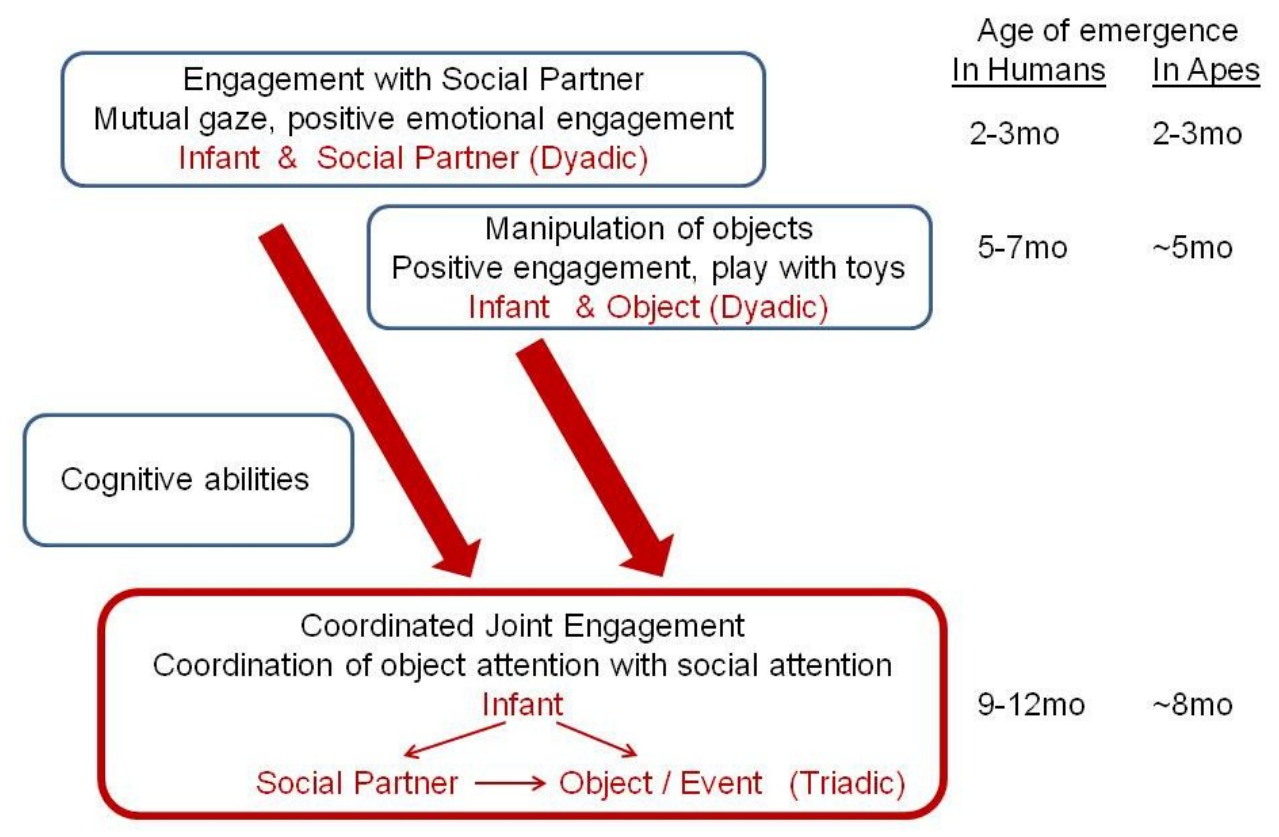

Figure 2 Social cognition develops in human and in chimpanzee infants. Joint attention is a triadic skill that develops from cognitive abilities entwined with developmental histories of previous dyadic engagements with social partners and with objects (Bard et al. 2014b). Ages of emergence in these dyadic and triadic skills follow similar timelines in human and chimpanzee infants.

These two strands of dyadic engagement (infants with social partners and infants with objects) intertwine with emerging cognitive abilities to allow infants to engage triadically in the final three months of the first year of life. Around 12 months of age, infants respond to adult bids and initiate joint attention by showing, offering, pointing to, and requesting objects, amid other shared practices (Racine \& Carpendale 2007). Studies from the Western middle-class perspectives emphasize the independent agency of the one-year-old infant who is given the lead role in interactions (child-centered parenting style).

\section{Cultural Variation in Human Infants}

Infants' phenotypic expression of engagement with caregivers and engagement with objects varies across human cultures. Human infants from different cultures have different socioemotional experiences, i.e., different developmental histories. It should not be surprising, therefore, that the effects of particular human settings can be seen as early as the first several weeks of life (e.g., Bard 2005), and in many social, emotional, 
and interactional outcomes. For example, in rural and interdependent cultures, high value is placed on body movement and physical contact with young infants (Abels et al. 2005; Keller et al. 2005a; Rogoff et al. 1993). Therefore, the amount of mutual gaze between infants and caregivers is reduced compared with Western norms (Keller 2007). There is also cultural variation in socialization practices surrounding object manipulation (e.g., Bakeman et al. 1990). In two rural settings in India, for example, three-month-olds were not given any toys (Abels et al. 2005), and in many traditional subsistence and hunter/gatherer cultures, there is very little caregiver encouragement, support, or attention paid to infant object manipulation (Bakeman et al. 1990; Hewlett \& Lamb 2009; Rogoff et al. 1993).

Infants in traditional, agrarian communities are socialized to value social harmony and obedience and to follow the caregiver's lead (adult-centered parenting style: Greenfield et al. 2003, Keller et al. 2004). In these cultures, infants are expected to comply with adult demands, and they do not command adults to follow their wishes (e.g., Gaskins 2006). Not only do infants in non-Western and rural settings spend significantly less time in joint attention activities, but they also exhibit significantly fewer pointing and showing gestures than do infants from Western, urban settings (Bakeman et al. 1990, Carpenter et al. 1998; Clarke-Stewart 1973; Salomo \& Liszkowski 2012).

\section{Human Infants Raised in Severely Deprived Environments}

Owing to government policies in the 1960s, many Romanian infants were raised in orphanages that did not provide the kinds of emotional and other interactive experiences that human children typically experience. In these orphanages, infants spent 17.5 hours per day alone in their cribs (Vorria et al. 2003). Studies have shown deleterious effects on cognitive, socioemotional development and attachment relationships in tragically impoverished and neglected populations [Hennighausen \& Lyons-Ruth 2006; Nelson et al. 2007; Rutter et al. 1999, 2010; Rutter \& Engl. Rom. Adopt. (ERA) Study Team 1998; Spitz 1946]. Human infants reared in Romanian orphanages had severely impaired or absolutely no joint attention skills (Kaler \& Freeman 1994), and Rutter \& ERA (1998) found between 30 and 300 times the background incidence of autism-like symptoms and severe deficits in communicative competence. The effects of early institutional care were still evident in follow-ups at 11 years (Rutter et al. 2007). 
A prospective, randomized controlled experiment confirmed the earlier associations between prolonged privation and developmental outcomes (Nelson et al. 2007). Children randomly assigned to foster care (FCG) performed significantly better than did children randomly selected to remain in institutional care. For the FCG, adoption at two years of age or less was associated with better mental development scores than those associated with later adoption. Thus, both retrospective and prospective studies of human children exposed to unusual amounts of deprivation and neglect have identified long-term deleterious effects on cognitive functioning and socioemotional development, as well as an apparent dose-dependent response to institutional rearing (albeit with some remarkable potential for developmental catch-up, given subsequent good foster care; see, e.g., Rutter \& ERA 1998).

\section{THE DEVELOPMENT OF SOCIAL COGNITION IN CHIMPANZEES}

Although we have known for decades that developmental experiences impact cognitive development in chimpanzees, few studies have provided information on the role of experience in the development of social cognition in apes. In this section, we review the studies that support our conclusion that chimpanzee infants, like human infants, develop joint attention and cooperation (among other triadic skills), based on developmental histories of engagement with social partners and engagement with objects (Figure 2).

\section{Social Engagement in Chimpanzee Infants}

It is in the realm of socioemotional development that we find a high degree of comparability between chimpanzees and humans and the earliest effects of developmental experiences in chimpanzees (Bard 2000, 2003; Bard et al. 2011). Like human newborns, chimpanzee newborns smile with a play face to familiar sights and sounds at about four weeks of age and laugh in response to tickles in the second month of life (e.g., Bard 2003, 2005). Newborn chimpanzees imitate facial actions of caregivers (Bard 2007). By 30 days of age, the specific rearing environment impacts the affective quality and amount of face-to-face interactions (Bard et al. 2011). For example, the number of smiles seen in chimpanzee infants was significantly higher (given positive interactive experiences with humans) or significantly lower (given little or no exposure 
to en face interactions with humans) than in a group of human infants (raised in Providence, RI; Bard et al. 2011). If the chimpanzee infants experienced 30 days of interaction with their biological mother, then they did not smile during interactions with a human examiner but did smile in interactions with their mother (Bard 1994; Bard et al. 2011). Thus, the types of social stimuli with which chimpanzee infants engage $(a)$ develop, (b) differ depending on developmental experiences, and (c) are evident from very early in life, i.e., by 30 days of age.

By three months of age, the amount of face-to-face interaction between infants and their chimpanzee mothers differs as a function of the caregiving environment (Bard et al. 2005; see Lavelli \& Fogel 2002 for similar findings with human infants). Developmental experiences have dramatic effects in the preferred modality of mutual engagement; in some chimpanzees, face-to-face interactions emerge from six to eight weeks of age, whereas in other groups, close physical contact is the preferred modality for mutual engagement (Bard et al. 2005). There is a range in phenotypes of preferred mutual engagement between infants and social partners among primates (e.g., Abels et al. 2005; Bard 1994, 2009; Bard et al. 2005; Bard \& Russell 1999; Keller et al. 2005a,b; Plooij 1984; Rogoff et al. 1993).

\section{Chimpanzee Infant Engagement with Objects}

Chimpanzee infants and human infants engage with objects in similar playful and manipulative ways, in rearing environments in which object play is valued and nurtured (Bard \& Vauclair 1984; Fouts \& Mills 1997; Hayes \& Hayes 1954; Kellogg \& Kellogg 1933; Savage-Rumbaugh et al. 1998; Temerlin 1976). "Enriched" chimpanzee infants experience warm and available caregivers who scaffold, praise, and comment on infants' explorations with objects (e.g., Bard et al. 2013; Fouts \& Mills 1997); mother-reared chimpanzee infants experience continuous physical contact, enriched social experiences, and infant-led explorations of the physical world independent of social interactions (e.g., Boesch, 2012; Goodall 1986; van Lawick-Goodall, 1968); human-reared nursery chimpanzee infants have extremely limited experiences, restricted access to objects and to caregivers, and poor-quality and low levels of interactions surrounding object manipulation even when caregivers are present (see Bard et al. 2014b, figure S4; van IJzendoorn et al. 2009; Vauclair \& Bard 1983). A lack of exposure to objects in infancy can cause chimpanzees to be extremely fearful of new objects and avoid new objects 
even many years later (Menzel 1964). These rearing experiences can also impact object manipulations that require more cognitive complexity, e.g., using objects as tools. For example, Furlong and colleagues (2008) compared tool use performance in chimpanzees from three backgrounds: those that had highly enriched rearing for most of their lives; those that had standard laboratory nursery experiences throughout their lives (from Povinelli 2000); and those with standard laboratory nursery for the first one to two years of life, followed by eight years at a highly enriched US sanctuary. Tool use performance varied systematically, with more sophisticated performance displayed by those chimpanzees with more enriched backgrounds. Thus, in chimpanzees, developmental experiences with object engagement have long-term effects, including effects on more complex abilities such as using objects as tools.

\section{Triadic Skills (Joint Attention/Shared Attention) in Chimpanzee Infants}

For chimpanzees, as well as humans, the dyadic engagements with social partners and with objects serve as the foundation for the emergence of joint attention and other triadic skills (Figure 2) (Bard et al. 2014a, $\underline{b}$ ). A recent study demonstrated the presence of both joint attention and cooperation in chimpanzees as young as five months of age (Bard et al. 2014b). Joint attention was evident when young chimpanzees watched demonstrations or tried to imitate the object-related actions of social partners. The triadic skill of coordinated joint engagement in the social domain, i.e., cooperation, was evident when young chimpanzees anticipated actions (or reactions) of social partners in regular social games such as peek-a-boo or actively participated in the give-and-take of objects with a social partner. Previous developmental experience was a major, highly significant, factor predicting success in both types of social cognition (Bard et al. $\underline{2014 b})$.

Developmental experiences during the first year of life have meaningful and large impacts on joint attention, cooperation, attachment, and communication (Bard 2000,

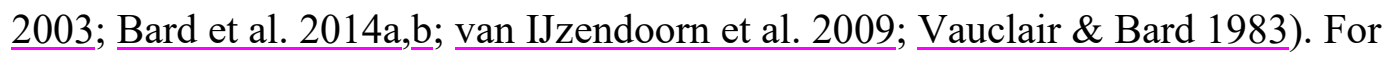
example, a chimpanzee toddler raised in an enriched family home exhibited pretend play with objects similar to that found in two-year-old humans (e.g., Hayes 1951). Young chimpanzees given explicit tuition have learned symbol systems comparable to those learned by 2--4-year-old human infants (e.g., Fouts \& Mills 1997; Gardner et al. 1989; Savage-Rumbaugh et al. 1993). 
Older chimpanzees exhibit this cognitive triadic capacity in many behaviors, such as intentional communication, cooperation, pointing, and social referencing (Bard et al.

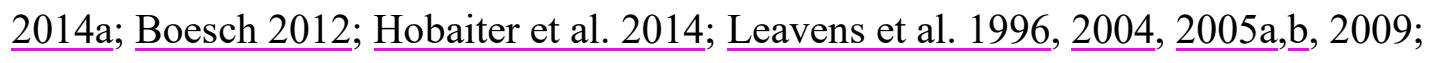
Leavens \& Hopkins 1998, 1999; Russell et al. 1997). Developmental experiences have long-lasting effects on the triadic social cognition skills involved in communication, imitation, and social cognition (e.g., Carpenter et al. 1995; Davenport et al. 1973; Horowitz 2003; Leavens et al., 2009; Leavens \& Hopkins 1998; Lyn et al. 2010; Menzel 1964; Rumbaugh et al. 2008; Russell et al. 2011; Savage-Rumbaugh 1986; Tomasello et al. 1993a,b). Not surprisingly, differential developmental experiences are evident in brain structures of adult chimpanzees (Bogart et al. 2014), similar to those proposed for humans (Fox et al. 2010). Group-specific variants of tool use and intentionally communicative gestures have been documented in wild chimpanzees (summarized in Whiten et al. 1999) as well as captive chimpanzees (Bard et al. 2014a; Call \& Tomasello 1997; Pika \& Liebal 2006; Pollick \& de Waal 2007). Thus, there can be no doubt that chimpanzees exhibit joint attention and also exhibit a significant amount of phenotypic variation in social cognition.

Chimpanzee infants, like human infants, develop emotional responses to caregivers, to examiners, and to objects, and these developmental experiences influence chimpanzees' motivations to engage, their pleasure (or fear) in cooperation, and their ability to perform cognitively complex activities (e.g., Bard 1998, 2005; Bard \& Gardner, 1996; Bard et al. 2014b; de Waal \& Ferrari 2010; Fouts \& Mills 1997; Menzel 1964; Menzel et al. 1970; Russell et al. 1997; Savage-Rumbaugh et al. 1993). We have known since the mid-1990s that young chimpanzees, like human toddlers, seek emotional messages about objects from favorite caregivers using a triadic skill known as social referencing (Russell et al. 1997). In social referencing, the chimpanzee's emotional bond with a caregiver supports the sharing of affective information about objects. Therefore, when the caregiver gives a negative message about the object (I don't like that object; it's scary), then the infant avoids the object. Alternatively, when the caregiver gives a positive message about an object (I like that object; it's a happy toy), the infant approaches and engages with the object. Additionally, some young chimpanzees may exhibit empathetic responses (comforting the caregiver when she expresses fear of the object) or spontaneous "showing" of objects (sharing attention to 
objects for no reason other than mutual interest; Carpenter et al. 1995, Russell et al. 1997). Boesch (2012) argued that social referencing was a component of theory of mind that occurred regularly in wild chimpanzees and furthermore presents convincing evidence of the chimpanzees' world 'being 'transformed' by the social culture to which an infant belongs" (pp. 149--50).

\section{Chimpanzees Raised in Institutional Nurseries}

Institutional nursery rearing of chimpanzees produces many deficits in emotional and cognitive development, just as similar rearing negatively influences cognitive development in humans (Smyke et al. 2007; van IJzendoorn et al. 2009; Zeanah et al. 2005). The conditions of the great ape nursery at the Yerkes Primate Center from 1956 to 1991 are briefly described in van IJzendoorn et al. (2009). In the period from 1956 to 1961, some laboratory chimpanzees were raised in isolation from birth through two years of age, but few, if any, of these subjects have been used for comparative studies of social cognition. Isolation rearing produced individuals with severe and persistent stereotyped behavior (rocking, self-clasping, eye poking, etc.; Davenport \& Menzel 1963), extreme fear of and avoidance of novel objects (e.g., Menzel 1964), an inability to cope with stress, persistent social deficits, and sexual deficits in adulthood (e.g., Rogers \& Davenport 1969). Isolation rearing, even if begun at two or three years of age (in wild-born chimpanzees) can cause persistent stereotypies and long-term deficits in social behavior (Kalcher et al. 2008).

In the 1970 s and early 1980 s, many nursery-reared chimpanzee infants were raised in pairs or triads. Peer-group rearing was a major improvement over isolation rearing in terms of psychological health, as chimpanzees formed attachments, albeit with peers (e.g., Bard \& Nadler 1983). In the late 1980s, with a new focus on psychological wellbeing (e.g., Fritz 1986), larger peer groups were formed, allowing 4--6 same-aged peers to live together continuously in enlarged spaces. This practice is known as standard care because it typifies institutional nursery care at the Yerkes Center and other institutional ape nurseries in the United States and Europe. During the average day, infant chimpanzees raised in a standard laboratory nursery spent $\sim 2$ of every 24 hours with an adult human caregiver (Bard et al. 2011; Bard et al. 2014b; Spijkerman et al. 1996). At Yerkes, this human-raised nursery care resulted in 59\% of 9-month-old chimpanzees having an abnormal attachment to an inanimate object (usually a towel) and $72 \%$ of 1 - 
year-olds having disorganized attachment systems with their favorite human caregivers (van IJzendoorn et al. 2009). Secure, insecure-avoidant, and insecure-ambivalent classifications represent the various organized strategies emerging from an infant-caregiver attachment system that allows infants to adapt to their environments. In contrast, disorganized attachment represents the absence of or major dysfunction in this system, an unfortunately common result when infants experience a neglectful or abusive environment (e.g., van IJzendoorn et al. 2009).

Only at the Yerkes Primate Center, from 1991 to 1995, was a responsive care (RC) nursery in place (Bard 1996). For four hours of each weekday, chimpanzees younger than one year had a specially trained human researcher/caregiver who was dedicated to nurturing the chimpanzees' species-typical communicative, social, and motor development (Bard et al. 2014a). Infants raised in RC, compared with standard care, had significantly higher levels of joint attention success and significantly higher cognitive scores (Bard et al. 2014b). However, even with the reduced caregiver--infant ratio (1.5 to 1 in $\mathrm{RC}$ versus 12.5 to 1 in the standard nursery) and the increase in caregiver contact (300 more minutes in RC), RC infants spent most of their time with same-aged peers in the absence of adult caregivers (16 of every 24 hours during the week and 22 of 24 hours during weekends and holidays). This rearing environment resulted in $42 \%$ of $\mathrm{RC}$ chimpanzees having a disorganized attachment system, significantly less than was found in the standard nursery group (van IJzendoorn et al. 2009) but substantially more than we find in human nonclinical populations.

\section{Implications}

A substantial amount of evidence speaks to the power of early developmental experiences in shaping the social cognition of chimpanzees, an area that has received very little attention (but see Bard \& Leavens 2009; Boesch 2007, 2012; Brüne et al. 2006; Kalcher et al. 2008; Leavens \& Bard 2011). Current comparative studies may state that the chimpanzee subjects were "human-raised," but typically, this designation means that they were raised in standard laboratory nurseries as described above (as were infants in the 1980s and 1990s). The percentage of disorganized attachment in human-raised nursery chimpanzees ( $72 \%$ in standard care) is comparable to that of human infants raised in very poor Greek or Romanian orphanages ( $\sim 67 \%$; see Bard 2012, figure 14.2, based on data derived from van IJzendoorn et al. 2009; Smyke et al. 2007; Zeanah et al. 
2005). Human-raised nursery-reared chimpanzees at 1 year of age had cognitive scores around 75, significantly lower than typically developing humans (with norms of 100; Bard et al. 2014b, figure S6) and remarkably similar to scores reported for human infants reared in substandard orphanages (an average of 66; Smyke et al. 2007). Raising chimpanzees in institutional nurseries significantly and negatively impacts their emotional and cognitive systems, with potentially long-lasting effects (Bard et al. 2014b; Brüne et al. 2006; Clay et al. 2012; Lyn et al. 2010; Menzel et al. 1963; Russell et al. 2011; van IJzendoorn et al. 2009), prompting Menzel (1964) to argue that the effects of raising chimpanzee infants in isolation were not noticeably different from the effects of any nursery rearing on chimpanzees. Even chimpanzees living as adults in physically enriched sanctuaries suffer long-lasting effects of early trauma and institutional care (Ferdowsian et al. 2011; Kalcher et al. 2008).

\section{CONSEQUENCES OF IGNORING DEVELOPMENT IN PRIMATE SOCIAL COGNITION}

Current evolutionary theories of social cognition rely on monocultural data for humans, i.e., collected from educated and well-off people from Western, industrialized, democratic countries (known as WEIRD; Henrich et al. 2010). In many domains of adult cognition, ranging from basic perception to complex social cognition, WEIRD adults are extreme outliers. Current mainstream comparative theories tend to ignore variations in social cognition, even from human infants raised in non-Western, rural cultures. It is vital to incorporate cross-cultural developmental data into theories of social cognition to determine the precursors and sequalae of joint attention that are universal in humans across the full range of ecocultural contexts (e.g., Vinden 1999). In building evolutionary scenarios, it is important to acknowledge that Western industrialized society is extremely unlike the environment(s) of evolutionary adaptedness (e.g., Foley 1996; Hewlett \& Lamb 2009; Hrdy 2009; Symons 1992). Consideration of the diversity in outcomes among humans is essential in building meaningful and valid evolutionary theories of social cognition.

We cannot measure the universality of a characteristic, or the cognitive capacity of a species, by investigating only members living in a single environmental niche. For example, some investigators assumed that the initiation of joint attention by pointing 
was universal and species-unique to humans, but this conclusion was based on studies with only Western middle-class infants (e.g., Butterworth 2003). People in some human cultures do not point with their fingers (therefore manual pointing is not universal in our species), and pointing reliably occurs in chimpanzees and other apes (therefore, pointing is not species-unique; Hobaiter et al. 2014; Leavens 2004; Leavens et al. 2005b; Wilkins 2003). It is only by documenting phenotypic variation in outcomes across groups that we can determine whether a characteristic is universal and/or species-unique (see Figure 3).
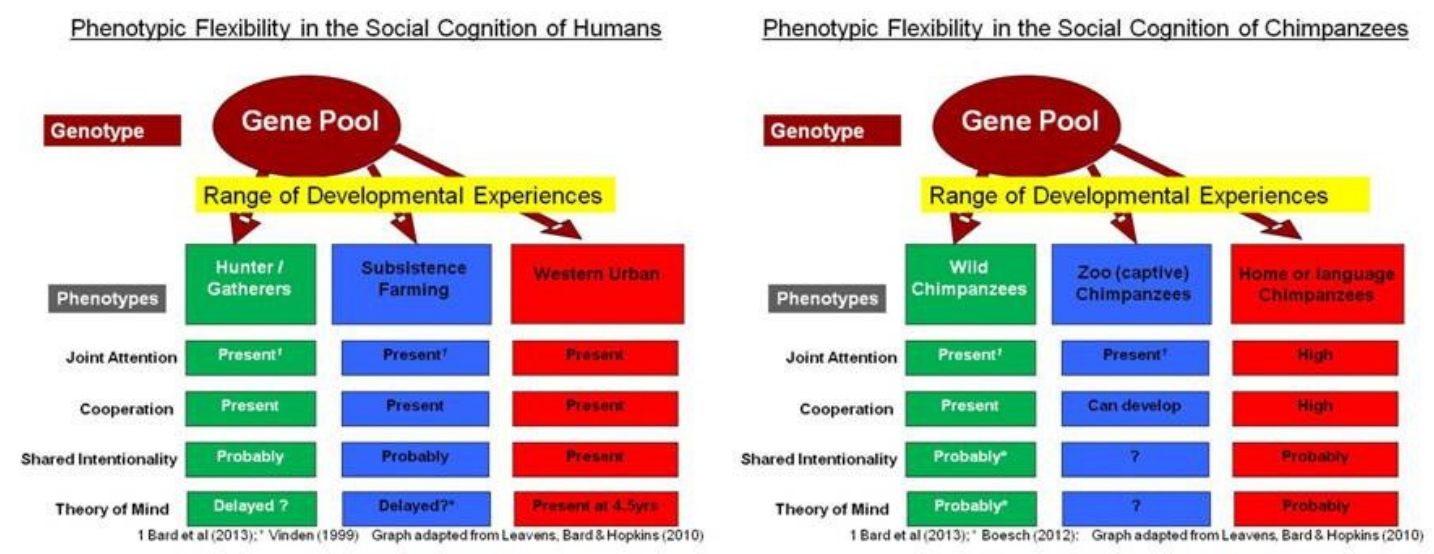

Figure 3 Phenotypic plasticity in social cognition. For future comparative studies we suggest this design that embraces the impact of developmental experiences on social cognition phenotypes (adapted from Leavens et al. 2005a, 2008, 2010). Species differences may be concluded if phenotypic outcomes do not overlap between chimpanzees and humans, given there is overlap in their developmental experiences.

On the basis of the data from studies of humans raised in Romanian orphanages and of apes reared in institutional nurseries, we purport that no researcher would assume that the institutionalized child is representative of the human species at large, and we argue that no researcher should assume that apes raised in institutional nurseries are the best representatives of their species (Leavens et al. 2010). Developmental experiences of such institutionalism clearly results in deficiencies in cognition, communication, and other socioemotional characteristics. One cannot generalize from the developmental profiles of these impoverished groups to the entire species. Unfortunately, very few contemporary researchers in comparative psychology give explicit consideration to how well their sample generalizes to the species (for exceptions, see Bard et al. 2014b; Boesch 2007; Furlong et al. 2008; Hayes 1951; Leavens 2004; Leavens et al. 2005a, 2008, 2010; Lyn et al. 2010; Racine et al. 2008). 


\section{PROPOSING A STUDY DESIGN THAT EMBRACES DEVELOPMENTAL EXPERIENCES}

We offer a research design that embraces development by documenting phenotypic variation in outcomes as a function of different developmental experiences (Figure 3) (Leavens et al. 2005a, 2008, 2010). When discussing social cognition outcomes, it is critical, yet a surprisingly uncommon practice, to consider the effects of development (especially, developmental experiences or rearing) in describing the capacities of apes, our closest evolutionary relatives. In the many ways we have identified here, the field would benefit from observing phenotypic variation in social cognition as a function of developmental experiences in humans and all other primates.

Multigroup comparisons are essential to specify whether types of social cognition are universal or species-unique because social cognitive outcomes of chimpanzees and humans are sensitive to developmental experiences. It remains a major task to systematically construct a model of the evolution of social cognition that builds on species comparisons containing developmental data (e.g., Deák et al. 2013; Jablonka \& Lamb 2007; Syal \& Finlay 2011). With this design, species differences could be concluded if there is no overlap in the phenotypic outcomes of chimpanzees and of humans, given that there is overlap in their developmental experiences. We propose that the use of this design (Figure 3), documenting the diversity and flexibility in outcomes and replacing the flawed experimental designs of the past (Figure 1), would support the construction of valid, logical, and grounded evolutionary theories of primate social cognition.

\section{DISCLOSURE STATEMENT}

The authors are not aware of any affiliations, memberships, funding, or financial holdings that might be perceived as affecting the objectivity of this review.

\section{ACKNOWLEDGEMENTS}

We thank all our colleagues, especially Bill Hopkins and Tim Racine, for helpful discussions related to developmental issues in primate social cognition. K.A.B. was supported, in part, by a Research Project grant from The Leverhulme Trust (F006780).

\section{LITERATURE CITED}


Abels M, Keller H, Mohite P, Mankodi H, Shastri J, et al. 2005. Early socialization contexts and social experiences of infants in rural and urban Gujarat, India. J. Cross-Cult. Psychol. $36: 717--38$

Adamson LB. 1996. Communication Development During Infancy. Boulder, CO: Westview

Bakeman R, Adamson LB. 1984. Coordinating attention to people and objects in motherinfant and peer-infant interaction. Child Dev. 55:1278--89

Bakeman R, Adamson LB, Konner M, Barr RG. 1990. !Kung infancy: the social context of object explorations. Child Dev. 61:794--809

Bard KA. 1994. Evolutionary roots of intuitive parenting: maternal competence in chimpanzees. Early Dev. Parent. 3:19--28

Bard KA. 1996. Responsive Care: A Behavioral Intervention Program for Nursery-Reared Chimpanzees. Tuscon, AZ: Jane Goodall Inst.

Bard KA. 1998. Social-experiential contributions to imitation and emotion in chimpanzees. In Intersubjective Communication and Emotion in Early Ontogeny, ed. S Bräten, pp. 208-27. Cambridge, UK: Cambridge Univ. Press

Bard KA. 2000. Crying in infant primates: insights into the development of crying in chimpanzees. In Crying as a Sign, a Symptom, and a Signal: Clinical Emotional and Developmental Aspects of Infant and Toddler Crying, ed. RG Barr, B Hopkins, JA Green, pp. 157--75. New York: Cambridge Univ. Press

Bard KA. 2003. Development of emotional expressions in chimpanzees Pan troglodytes. Ann. N. Y. Acad. Sci. 1000:88--90

Bard KA. 2005. Emotions in chimpanzee infants: the value of a comparative developmental approach to understand the evolutionary bases of emotion. In Emotional Development: Recent Research Advances, ed. J Nadel, D Muir, pp. 31--60. New York: Oxford Univ. Press

Bard KA. 2007. Neonatal imitation in chimpanzees (Pan troglodytes) tested with two paradigms. Anim. Cogn. 10:233--42

Bard KA. 2009. Social cognition: evolutionary history of emotional engagements with infants. Curr. Biol. 19:R941--43

Bard KA. 2012. Emotional engagement: how chimpanzee minds develop. In The Primate Mind: Built to Engage With Other Minds, ed. F de Waal, P Ferrari, pp. 224--45. Cambridge, MA: Harvard Univ. Press 
Bard KA, Bakeman R, Boysen ST, Leavens DA. 2014a. Emotional engagements predict and enhance social cognition in young chimpanzees. Dev. Sci. In press

Bard KA, Brent L, Lester B, Worobey J, Suomi SJ. 2011. Neurobehavioral integrity of chimpanzee newborns: comparisons across groups and across species reveal geneenvironment interaction effects. Infant Child Dev. 20:47--93

Bard KA, Dunbar S, Maguire-Herring V, Veira Y, Hayes KG, McDonald K. 2014b. Gestures and socio-emotional communicative development in chimpanzee infants. Am. J. Primat. 76:14--29

Bard KA, Gardner KH. 1996. Influences on development in infant chimpanzees: enculturation, temperament, and cognition. In Reaching into Thought: The Minds of the Great Apes, ed. AE Russon, KA Bard, ST Parker, pp. 235--56. New York: Cambridge Univ. Press

Bard KA, Hewlett B, Ross K, Wallauer B, Keller H, et al. 2013. The effects of lived experiences on primate social cognition. Folia Primat. 84:246 (Abstr.)

Bard KA, Leavens DA. 2009. Socio-emotional factors in the development of joint attention in human and ape infants. See Röska-Hardy \& Neumann-Held 2009, pp. 89--104

Bard KA, Myowa-Yamakoshi M, Tomonaga M, Tanaka M, Costall A, Matsuzawa T. 2005. Group differences in the mutual gaze of chimpanzees Pan troglodytes. Dev. Psychol. 41:616--24

Bard KA, Nadler RD. 1983. The effect of peer separation in young chimpanzees (Pan troglodytes). Am. J. Primat. 5:25--37

Bard KA, Russell CL. 1999. Evolutionary foundations of imitation: social cognitive and developmental aspects of imitative processes in non-human primates. In Imitation in Infancy, ed. J Nadel, G Butterworth, pp. 89--123. New York: Cambridge Univ. Press

Bard KA, Vauclair J. 1984. The communicative context of object manipulation in ape and human adult-infant pairs. J. Hum. Evol. 13:181--90

Boesch C. 2007. What makes us human (Homo sapiens)? The challenge of cognitive crossspecies comparison. J. Comp. Psych. 121:227--40

Boesch C. 2012. Wild Cultures: A Comparison between Chimpanzee and Human Cultures. Cambridge, UK: Cambridge Univ. Press

Bogart SL, Bennett AJ, Schapiro SJ, Reamer LA, Hopkins WD. 2014. Different early rearing experiences have long-term effects on cortical organization in captive chimpanzees (Pan 
troglodytes). Dev. Sci. 17:161--74

Brüne M, Brüne-Cohrs U, McGrew WC, Preuschoft S. 2006. Psychopathology in great apes: concepts, treatment options and possible homologies to human psychiatric disorders. Neurosci. Biobehav. Rev. 30:1246--59

Butterworth G. 2003. Pointing is the royal road to language for babies. In Pointing: Where Language, Culture, and Cognition Meet, ed. S Kita, pp. 9--33. Mahwah, NJ: Erlbaum Byrne RW, Whiten A, eds. 1988. Machiavellian Intelligence: Social Expertise and the Evolution of Intellect in Monkeys, Apes, and Humans. Oxford, UK: Oxford Univ. Press

Call J, Tomasello M, eds. 1997. The Gestural Communication of Apes and Monkeys. New York: Erlbaum

Carpenter M, Nagell K, Tomasello M. 1998. Social cognition, joint attention, and communicative competence from 9 to 15 months of age. Monogr. Soc. Res. Child Dev. Vol. 63 (4), Ser. No. 255

Carpenter M, Tomasello M, Savage-Rumbaugh S. 1995. Joint attention and imitative learning in children, chimpanzees, and enculturated chimpanzees. Soc. Dev. 4:217--37

Clarke-Stewart KA. 1973. Interactions between Mothers and Their Young Children: Characteristics and Consequences. Monogr. Soc. Res. Child Dev. Vol. 38, Ser. No. 153. Hoboken, NJ: Wiley

Clay AW, Bard KA, Bloomsmith MA, Maple TL, Marr MJ, Rollins H. 2012. Disorganized versus organized attachment styles in captive laboratory-housed chimpanzees (Pan troglodytes). Am. J. Primat. 74:57 (Abstr.)

Davenport RK, Menzel EW. 1963. Stereotyped behavior of the infant chimpanzee. Arch. Gen. Psychiatry 8:99--104

Davenport RK, Rogers CM, Rumbaugh DM. 1973. Long-term cognitive deficits in chimpanzees associated with early impoverished rearing. Dev. Psychol. 9:343--47

de Waal FBM, Ferrari PF. 2010. Toward a bottom-up perspective on animal and human cognition. Trends Cogn. Sci. 14:201--7

Deák GO, Triesch J, Krasno A, de Barbaro K, Robledo M. 2013. Learning to share: the emergence of joint attention in human infancy. In Cognition and Brain Development: Converging Evidence from Various Methodologies, ed. BR Kar, pp. 173--210. Washington, DC: Am. Psychol. Assoc.

Dean LG, Kendal RL, Schapiro SJ, Thierry B, Laland KN. 2012. Identification of the social 
and cognitive processes underlying human cumulative culture. Science 335:1114--18

Dunbar RIM. 1988. The social brain hypothesis. Evol. Anthropol. 6:178--90

Ferdowsian HR, Durham DL, Kimwele C, Kranendonk G, Otali E, et al. 2011. Signs of mood and anxiety disorders in chimpanzees. PLoS ONE 6:e19855

Foley R. 1996. The adaptive legacy of human evolution: a search for the environment of evolutionary adaptedness. Evol. Anthropol. 4:194--203

Fouts RS, Mills S. 1997. Next of Kin: My Conversations with Chimpanzees. New York: HarperCollins

Fox SE, Levitt P, Nelson CA III. 2010. How the timing and quality of early experiences influence the development of brain architecture. Child Dev. 81:28--40

Fragaszy DM, Bard KA. 1997. Comparison of development and life history in Pan and Cebus. Int. J. Primat. 18:683--701

Fritz J. 1986. Resocialization of asocial chimpanzees. In Primates: The Road to SelfSustaining Populations, ed. K Bernirschke, pp. 351--59. New York: Springer

Furlong EE, Boose KJ, Boysen ST. 2008. Raking it in: the impact of enculturation on chimpanzee tool use. Anim. Cogn. 11:83--97

Gardner RA, Gardner BT, Van Cantfort TE, eds. 1989. Teaching Sign Language to Chimpanzees. Albany: State Univ. NY Press

Gaskins S. 2006. Cultural perspectives on infant-caregiver interaction. In Roots of Human Sociality: Culture, Cognition and Interaction, ed. NJ Enfield, SC Levinson, pp. 279--98. Oxford, UK: Oxford Univ. Press

Goodall J. 1986. The Chimpanzees of Gombe: Patterns of Behavior. Cambridge, MA: Belknap

Greenfield PM, Keller H, Fuligni A, Maynard A. 2003. Cultural pathways through universal development. Annu. Rev. Psychol. 54:461--90

Hayes C. 1951. The Ape in our House. New York: Harper

Hayes KJ, Hayes C. 1954. The cultural capacity of chimpanzee. Hum. Biol. 26:288--303

Hennighausen KH, Lyons-Ruth K. 2006. Disorganization of behavioral and attentional strategies toward primary attachment figures: from biologic to dialogic processes. In Attachment and Bonding: A New Synthesis, ed. CS Carter, L Ahnert, KE Grossman, SB Hrdy, ME Lamb, et al., Dahlem Workshop Ser. Max Planck Inst., pp. 269--300. Cambridge, MA: MIT Press 
Henrich J, Heine SJ, Norenzayan A. 2010. The weirdest people in the world? Behav. Brain Sci. 33:61--135

Herrmann E, Call J, Hernández-Lloreda MV, Hare B, Tomasello M. 2007. Humans have evolved specialized skills of social cognition: the cultural intelligence hypothesis. Science 317:1360--66

Hewlett BS, Lamb ME. 2009. Hunter-Gatherer Childhoods: Evolutionary, Developmental and Cultural Perspectives. New Brunswick, NJ: Transaction

Hobaiter C, Leavens DA, Byrne RW. 2014. Deictic gesturing in wild chimpanzees (Pan troglodyes)? Some possible cases. J. Comp. Psychol. 128(1): 82-7 Horowitz AC. 2003. Do humans ape? Or do apes human? Imitation and intention in humans (Homo sapiens) and other animals. J. Comp. Psychol. 117:325--36

Hrdy SB. 2009. Mothers and Others: The Evolutionary Origins of Mutual Understanding. Cambridge, MA: Harvard Univ. Press

Humphrey NK. 1976. The social function of intellect. In Growing Points in Ethology, ed. PPG Bateson, RA Hinde, pp. 303--17. Cambridge, UK: Cambridge Univ. Press

Jablonka E, Lamb MJ. 2007. Précis of Evolution in Four Dimensions. Behav. Brain Sci. $30: 353-92$

Jolly A. 1966. Lemur social behavior and primate intelligence. Science 153:501--6

Kalcher E, Franz C, Crailsheim K, Preuschoft S. 2008. Differential onset of infantile deprivation produces distinctive long-term effects in adult ex-laboratory chimpanzees (Pan troglodytes). Dev. Psychobiol. 50:777--88

Kaler SR, Freeman BJ. 1994. Analysis of environmental deprivation: cognitive and social development in Romanian orphans. J. Child Psychol. Psychiatry 35:769--81

Keller H. 2007. Cultures of Infancy. Mahwah, NJ: Erlbaum

Keller H, Abels M, Lamm B, Yovsi R, Voelker S, Lakhani A. 2005a. Ecocultural effects on early infant care: a study in Cameroon, India, and Germany. Ethos 33:512--41

Keller H, Lohaus A, Kuensemueller P, Abels M, Yovsi R, et al. 2004. The bio-culture of parenting: evidence from five cultural communities. Parent. Sci. Prac. 4:25--50

Keller H, Voelker S, Yovsi RD. 2005b. Conceptions of parenting in different cultural communities: the case of West African Nso and northern German women. Soc. Dev. $14: 158--80$

Kellogg WN, Kellogg LA. 1933. The Ape and the Child: A Study of Early Environmental 


\section{Influence upon Early Behavior. New York: McGraw-Hill}

Lavelli M, Fogel A. 2002. Developmental changes in mother-infant face-to-face communication: birth to 3 months. Dev. Psychol. 38:288--305

Leavens DA. 2004. Manual deixis in apes and humans. Interact. Stud. 5:387--408

Leavens DA, Bard KA. 2011. Environmental influences on joint attention in great apes: implications for human cognition. J. Cogn. Educ. Psychol. 10:9--31

Leavens DA, Bard KA, Hopkins WD. 2010. BIZARRE chimpanzees do not represent "the chimpanzee". Behav. Brain Sci. 33:100--1

Leavens DA, Hopkins WD. 1998. Intentional communication by chimpanzees: a crosssectional study of the use of referential gestures. Dev. Psychol. 34:813--22

Leavens DA, Hopkins WD. 1999. The whole-hand point: the structure and function of pointing from a comparative perspective. J. Comp. Psychol. 113:417--25

Leavens DA, Hopkins WD, Bard KA. 1996. Indexical and referential pointing in chimpanzees (Pan troglodytes). J. Comp. Psychol. 110:346--53

Leavens DA, Hopkins WD, Bard KA. 2005a. Understanding the point of chimpanzee pointing: epigenesis and ecological validity. Curr. Dir. Psychol. Sci. 14:185--89

Leavens DA, Hopkins WD, Bard KA. 2008. The heterochronic origins of explicit reference. In The Shared Mind: Perspectives on Intersubjectivity, ed. J Zlatev, TP Racine, C Sinha, E Itkonen, pp. 187--214. Amsterdam: John Benjamins

Leavens DA, Hopkins WD, Thomas RK. 2004. Referential communication by chimpanzees (Pan troglodytes). J. Comp. Psychol. 118:48--67

Leavens DA, Racine TP. 2009. Joint attention in apes and humans: Are humans unique? J. Conscious. Stud. 16:240--67

Leavens DA, Racine TP, Hopkins WD. 2009. The ontogeny and phylogeny of non-verbal deixis. In The Prehistory of Language, ed. C Knight, R Botha, pp. 142--65. Oxford, UK: Oxford Univ. Press

Leavens DA, Russell JL, Hopkins WD. 2005b. Intentionality as measured in the persistence and elaboration of communication by chimpanzees (Pan troglodytes). Child Dev. 76:291$-306$

Lyn H, Russell JL, Hopkins WD. 2010. The impact of environment on the comprehension of declarative communication in apes. Psychol. Sci. 21:360--65

Menzel EW Jr. 1964. Patterns of responsiveness in chimpanzees reared through infancy 
under conditions of environmental restriction. J. Psychol. Res. 27:337--65

Menzel EW Jr, Davenport RK Jr, Rogers CM. 1970. The development of tool using in wildborn and restriction-reared chimpanzees. Folia Primatol. 12:273--83

Menzel EW Jr, Davenport RK Jr, Rogers CM. 1963. The effects of environmental restriction upon the chimpanzee's responsiveness to objects. J. Comp. Physiol. Psychol. 56:78--85

Moll H, Tomasello M. 2007. Cooperation and human cognition: the Vygotskian intelligence hypothesis. Phil. Trans. R. Soc. B 362:639--48

Nelson CA 3rd, Zeanah CH, Fox NA, Marshall PJ, Smyke AT, Guthrie D. 2007. Cognitive recovery in socially deprived young children: the Bucharest Early Intervention Project. Science 318:1937--40

Parker ST, Gibson KR. 1977. Object manipulation, tool use and sensorimotor intelligence as feeding adaptations in cebus monkeys and great apes. J. Hum. Evol. 6:623--41

Parker ST, Gibson KR. 1979. A developmental model for the evolution of language and intelligence in early hominids. Behav. Brain Sci. 2:367--81

Pika S, Liebal K. 2006. Differences and similarities between the natural gestural communication of the great apes and human children. In Proc. Int. Conf. Evol. Lang., 6th, ed. A Cangelosi, ADM Smith, K Smith, pp. 267--74. London: World Sci.

Plooij FX. 1984. The Behavioral Development of Free-living Chimpanzee Babies and Infants. New York: Ablex

Pollick AS, de Waal FBM. 2007. Ape gestures and language evolution. Proc. Natl. Acad. Sci. USA 104:8184--89

Povinelli DJ. 2000. Folk Physics for Apes: The Chimpanzee's Theory of How the World Works. Oxford, UK: Oxford Univ. Press

Premack D, Woodruff G. 1978. Does the chimpanzee have a theory of mind? Behav. Brain Sci. 4:515--26

Racine TP, Carpendale JIM. 2007. The role of shared practices in joint attention. Br. J. Dev. Psychol. 25:3--25

Racine TP, Leavens DA, Susswein N, Wereha TJ. 2008. Conceptual and methodological issues in the investigation of primate intersubjectivity. In Enacting Intersubjectivity: A Cognitive and Social Perspective to the Study of Interactions, ed. F Morganti, A Carassa, G Riva, pp. 65--79. Amsterdam: IOS

Rakoczy H. 2009. Collective intentionality and the roots of human societal life. See Röska- 
Hardy \& Neumann-Held 2009, pp. 106--21

Rogers CM, Davenport RK. 1969. Effects of restricted rearing on sexual behaviour of chimpanzees. Dev. Psychol. 1:200--4

Rogoff B, Mistry J, Goncu A, Mosier C, Chavajay P, Heath S. 1993. Guided Participation in Cultural Activity By Toddlers and Caregivers. Monogr. Soc. Res. Child Dev. Vol. 58, Ser. No. 236. Hoboken, NJ: Wiley

Röska-Hardy L, Neumann-Held EM, eds. 2009. Learning from Animals? Examining the Nature of Human Uniqueness. London: Psychology Press

Rumbaugh D, Washburn DA, King JE, Beran MJ, Gould K, Savage-Rumbaugh ES. 2008.

Why some apes imitate and/or emulate observed behavior and others do not: fact, theory, and implications for our kind. J. Cogn. Educ. Psychol. 7:100--10

Russell CL, Bard KA, Adamson LB. 1997. Social referencing by young chimpanzees (Pan troglodytes). J. Comp. Psychol. 111:185--91

Russell JL, Lyn H, Schaeffer JA, Hopkins WD. 2011. The role of socio-communicative rearing environments in the development of social and physical cognition in apes. Dev. Sci. 14:1459--70

Rutter M, Anderson-Wood L, Beckett C, Bredenkamp D, Castle J, et al. 1999. Quasi-autistic patterns following severe early global privation. J. Child Psychol. Psychiatry 40:537--49

Rutter M, Beckett C, Castle J, Colvert E, Kreppner J, et al. 2007. Effects of profound early institutional deprivation: an overview of findings from a UK longitudinal study of Romanian adoptees. Eur. J. Dev. Psychol. 4:332--50

Rutter M, Engl. Rom. Adopt. (ERA) Study Team. 1998. Developmental catch-up, and deficit, following adoption after severe global early privation. J. Child Psychol. Psychiatry 39:465--76

Rutter M, Sonuga-Barke EJ, Beckett C, Castle J, Kreppner J, et al. 2010. DeprivationSpecific Psychological Patterns: Effects of Institutional Deprivation. Monogr. Soc. Res. Child Dev. Vol. 75, Ser. No. 295. Hoboken, NJ: Wiley

Salomo D, Liszkowski U. 2012. Sociocultural settings influence the emergence of prelinguistic deictic gestures. Child Dev. 84:1296--307

Savage-Rumbaugh ES. 1986. Ape Language: From Conditioned Response to Symbol. New York: Columbia Univ. Press

Savage-Rumbaugh ES, Murphy J, Sevcik RA, Brakke KE, Williams SL, Rumbaugh DM. 
1993. Language Comprehension in Ape and Child. Monogr. Soc. Res. Child Dev. Vol. 58, Ser. No. 233. Hoboken, NJ: Wiley

Savage-Rumbaugh ES, Shanker SG, Taylor TJ. 1998. Apes, Language, and the Human Mind. Oxford, UK: Oxford Univ. Press

Smyke AT, Koga SF, Johnson DE, Fox NA, Marshall PJ, et al. 2007. The caregiving context in institution-reared and family-reared infants and toddlers in Romania. J. Child Psychol. Psychiatry 48:210--18

Spijkerman RP, Dienske H, van Hooff JARAM, Jens W. 1996. Differences in variability, interactivity and skills in social play of young chimpanzees living in peer groups and in a large family zoo group. Behaviour 133:717--39

Spitz RA. 1946. Anaclitic depression. Psychoanal. Stud. Child 2:313--42

Suomi SJ. 2004. How gene-environment interactions influence emotional development in rhesus monkeys. In Nature and Nurture: The Complex Interplay of Genetic and Environmental Influences on Human Behavior and Development, ed. C Garcia Coll, EL Bearer, RM Lerner, pp. 35-51. Mahwah, NJ: Erlbaum

Syal S, Finlay BL. 2011. Thinking outside the cortex: social motivation in the evolution and development of language. Dev. Sci. 14:417--430

Symons D. 1992. On the use and misuse of Darwinism in the study of human behavior. In The Adapted Mind: Evolutionary Psychology and the Generation of Culture, ed. JH Barkow, LE Cosmides, J Tooby, pp. 137--62. New York: Oxford Univ. Press

Temerlin MK. 1976. Lucy: Growing Up Human. London: Souvenir

Tennie C, Call J, Tomasello M. 2009. Ratcheting up the rachet: on the evolution of cumulative culture. Phil. Trans. R. Soc. B 364:2405--15

Tomasello M, Carpenter M, Call J, Behne T, Moll H. 2005. Understanding and sharing intentions: the origins of cultural cognition. Behav. Brain Sci. 28:675--91

Tomasello M, Kruger AC, Ratner HH. 1993a. Cultural learning. Behav. Brain Sci. 16:495-511

Tomasello M, Savage-Rumbaugh ES, Kruger AC. 1993b. Imitative learning of actions on objects by children, chimpanzees, and enculturated chimpanzees. Child Dev. 64:1688-705

Trevarthen C. 1979. Communication and cooperation in early infancy: a description of primary intersubjectivity. In Before Speech: The Beginnings of Interpersonal 
Communication, ed. M Bullowa, pp. 321--47. New York: Cambridge Univ. Press

Trevarthen C, Aitken KJ. 2001. Infant intersubjectivity: research, theory, and clinical applications. J. Child Psychol. Psychiatry 42:3--48 van IJzendoorn MH, Bard KA, Bakermans-Kranenburg MJ, Ivan K. 2009. Enhancement of attachment and cognitive development of young nursery-reared chimpanzees in responsive versus standard care. Dev. Psychobiol. 51:173--85

van Lawick-Goodall J. 1968. The behaviour of free-living chimpanzees in the Gombe Stream Nature reserve. Anim. Behav. Monogr. 1:161--311 Vauclair J, Bard KA. 1983. Development of manipulations with objects in ape and human infants. J. Hum. Evol. $12: 631--45$

Vinden PG. 1999. Children's understanding of mind and emotion: a multi-culture study. Cogn. Emot. 13:19--48

Vorria P, Papaligoura Z, Dunn J, van IJzendoorn MH, Steele H, et al. 2003. Early experiences and attachment relationships of Greek infants raised in residential group care. J. Child Psych. Psychiatry 44:1208--20

Whiten A, Byrne RW. 1988. Tactical deception in primates. Behav. Brain Sci. 11:233--44

Whiten A, Goodall J, McGrew WC, Nishida T, Reynolds V, et al. 1999. Cultures in chimpanzees. Science 399:682--85

Wilkins D. 2003. Why pointing with the index finger is not a universal (in sociocultural and semiotic terms). In Pointing: Where Language, Culture, and Cognition Meet, ed. S Kita, pp. 171--215. Mahwah, NJ: Erlbaum

Zeanah CH, Smyke AT, Koga SF, Carlson E. 2005. Attachment in institutionalized and community children in Romania. Child Dev. 76:1015--28 